\title{
Vitamina E como solução antiaderente em processos cirúrgicos do trato genitourinário de ovinos
}

Luisa Pucci Bueno Borges ${ }^{[a, b]}$, Vitor Foroni Casas ${ }^{[a]}$, Pedro Paulo Maia Teixeira ${ }^{[b]}$, Ewaldo de Mattos Junior ${ }^{[a]}$, Ilan Munhoz Ayer ${ }^{[a]}$, Maria Augusta Adami Pereira dos Santos ${ }^{[a]}$, Débora de Oliveira Garcia ${ }^{[a]}$, Simone Bonattini Martinez ${ }^{[a]}$, Renata Sitta Gomes Mariano[c], Felipe Farias Pereira da Câmara Barros ${ }^{[a]}$

\footnotetext{
[a] Universidade de Franca (UNIFRAN), Franca, SP, Brasil

[b] Universidade Federal do Pará (UFPA), Castanhal, PA, Brasil

[c] Universidade Estadual Paulista (UNESP), Jaboticabal, SP, Brasil
}

*Autor correspondente

e-mail: luisa_pucci@hotmail.com

\section{Resumo}

Cirurgias abdominais são necessárias para realização de diversas biotécnicas da reprodução em pequenos ruminantes. Pequenos ruminantes não apresentam ovários facilmente acessíveis pelas uterina e retal, tornando-se a laparotomia recurso importante na reprodução desses animais. No entanto, uma das principais complicações desses procedimentos é a formação de aderências abdominais. Neoformações podem provocar sequelas graves em reprodutoras, deixando-as inutilizáveis. Assim, medidas profiláticas têm sido tomadas na tentativa de evitar esses problemas indesejados. Algumas delas são aplicações de soluções antiaderentes durante o ato cirúrgico. Vitamina E, por ser um componente fisiológico que age contra a peroxidação lipídica e como antioxidante combatente de radicais livres, tem sido testada como uma dessas substâncias que podem prevenir as adesões de órgãos abdominais. Partindo desse princípio, objetivouse com esse trabalho avaliar a vitamina E como solução antiaderente em procedimentos cirúrgicos que lesionem tecidos do trato geniturinário. Esse estudo foi aprovado pela Comissão de Ética no Uso de Animais da Universidade de Franca (protocolo no 2713070316), no qual 11 ovelhas foram divididas aleatoriamente em dois grupos experimentais: um controle, $(\mathrm{GC}, \mathrm{n}=5)$ e um grupo tratamento (GVE, $\mathrm{n}=6$ ). Os animais foram inicialmente posicionados em decúbito dorsal e em trendelenburg a $45^{\circ}$ para melhor acesso aos órgãos geniturinários. Em seguida, acessou-se a cavidade abdominal por meio de incisão retro-umbilical (10 cm de comprimento); ao identificar útero, ovários e tubas uterinas, estes foram exteriorizados e isolados com compressas estéreis. Utilizando método de cauterização bipolar, três locais do corno uterino direito e um ponto do ovário foram cauterizados (durante 3 segundos), esperando-se que essas lesões promoveriam a formação de aderências. No fim do procedimento, a cavidade abdominal foi banhada com $20 \mathrm{~mL}$ de 
vitamina E, enquanto não houve aplicação de substâncias no grupo controle. Após 21 dias, esses animais foram submetidos ao procedimento de videolaparoscopia, com objetivo de avaliação macroscópica das possíveis aderências formadas. Inicialmente, avaliou-se se havia ou não aderências envolvendo tais órgãos. Posteriormente, quando presentes, elas foram classificadas com relação à quantidade de neoformações. A proporção de aderências peritoneais entre os grupos foi comparada pelo teste exato de Fischer e o número de aderências observado pelo teste de Kruskal-Wallis. 0 nível de significância foi fixado em 5\% para todas as análises $(\mathrm{P}>0,05)$, constatando-se que o número de aderência foi maior $(\mathrm{P}=0,032)$ no grupo controle do que no grupo tratado. A proporção de aderências foi similar ( $\mathrm{P}=0,819)$ entre os grupos - 80\% $(4 / 5)$ para GC e 83\% (5/6) para GVE - e o número de aderência foi maior ( $\mathrm{P}=0,032)$ no GC. Resultado semelhante também já foi obtido em ratos com aplicação de vitamina E intraperitoneal. Concluiu-se que a utilização da vitamina E como solução antiaderente não impediu a formação de aderências, mas as reduziu em quantidade quando comparadas ao grupo controle. 